\title{
Arterial Hypertension in Children with Chronic Kidney Diseases
}

\author{
Karimdzhanov Ilkhamdzhan*, Rakhmanova Lola, Iskanova Gulshan, Israilova Nigora, \\ Yusupova Gulnoza, Karimova Umida
}

Department of Children Diseases N2 of Tashkent Medical Academy, Tashkent, Uzbekistan

\section{Email address:}

ilkhamdjan.5346@gmail.com (K. Ilkhamdzhan), lolarahmanova1961@gmail.com (R. Lola),gulshan1972iskanova@gmail.com (I. Gulshan), nigora99@gmail.com (I. Nigora), doctorgulnoza77@gmail.com (Y. Gulnoza), ukarimova777@gmail.com (K. Umida)

${ }^{*}$ Corresponding author

\section{To cite this article:}

Karimdzhanov Ilkhamdzhan, Rakhmanova Lola, Iskanova Gulshan, Israilova Nigora, Yusupova Gulnoza, Karimova Umida. Arterial Hypertension in Children with Chronic Kidney Diseases. American Journal of Pediatrics. Special Issue: Chronic Kidney Disease in Children. Vol. 6, No. 2, 2020, pp. 109-116. doi: 10.11648/j.ajp.20200602.18

Received: February 18, 2020; Accepted: March 4, 2020; Published: March 10, 2020

\begin{abstract}
Arrterial hypertension (HTN) is one of the most common sequelae of chronic kidney disease (CKD) in children. In children with chronic kidney disease (CKD) HTN is several times higher than in the general pediatric population. With progression of CKD, HTN increases, reaching $45-60 \%$ in dialysis patients. The regulation of hypertension in children is mandatory in the treatment of CKD due to the fact that hypertension is often goes unrecognized, insufficiently controlled and often masked. The etiology of hypertension is different depending on the age of diagnosis. In newborns and young children, hypertension occurs due to renovascular diseases such as renal venous thrombosis, renal artery stenosis and other renal parenchymal diseases. HTN is considered a marker for disease severity in CKD and is a risk factor for accelerated deterioration of kidney function as well as for cardiovascular disease. Activation of the renin-angiotensin-aldosterone system plays a pivotal role in renal hypertension. Obesity and hyperuricemia are the risk factors for HTN in CKD in children and lead to the progression of CKD. HTN-induced target organ damage (TOD) manifests as microalbuminuria/proteinuria, retinopathy, increase in intima media thickness, atherosclerosis, reduced arterial compliance, cognitive impairment, and left ventricular hypertrophy (LVH). In adults and children with CKD, ABPM has been found to be superior than causal blood pressure to diagnose hypertension and to monitor adequacy of treatment. The main drug therapy used in children with HTN and CKD consists of ACE inhibitors. Strict BP control and limitation of proteinuria with ACE inhibitors and angiotensin receptor blockers (ARB) can slow the progression of CKD.
\end{abstract}

Keywords: Chronic Kidney Disease, Hypertension, Children

\section{Introduction}

Arrterial hypertension (HTN) is one of the most common sequelae of chronic kidney disease (CKD) in children. In children with chronic kidney disease (CKD) HTN is several times higher than in the general pediatric population. With progression of CKD, HTN increases, reaching $45-60 \%$ in dialysis patients $[1,2]$. There are now many studies demonstrating an interaction between CKD and HTN, with HTN likely hastening the progression of CKD toward endstage renal disease $[3,4,5]$. The regulation of hypertension in children is mandatory in the treatment of CKD due to the fact that hypertension is often goes unrecognized, insufficiently controlled and often masked [6,7]. Violation of vascular regulation, fluid overload, increased cardiac output, and peripheral vascular resistance, individually or in combination, can lead to HTN in CKD. Hyper-reninemia occurs probably due to renin secretion in poorly perfused areas such as cysts and scars or after microangiopathic damage or tubulo-interstitial inflammation [8] and leads to angiotensin II-mediated vasoconstriction, as well as aldosterone-mediated salt retention, thus increasing both total peripheral resistance and blood volume. Additional delayed effects of a high angiotensin II tone include inflammation, cardiac hypertrophy and endothelial cell damage, mesangial 
cell proliferation and fibrosis [9, 10], which contribute further to HTN and end-organ damage. For adequate management of HTN and prevention of target organ damage, the use of modern methods for monitoring and controlling blood pressure is important [11]. At the same time, the diagnosis and treatment of HTN in children with CKD remains a problem today [8]. Antihypertensive drugs, including angiotensin converting enzyme (ACE) inhibitors, provide renoprotection and slow the progression of CKD in children with and without proteinuria [12]. The use of ACE inhibitors in CKD in children is often accompanied by hyperkalemia [13]. Monitoring blood pressure and diet are factors in the regulation of HTN, however, they are difficult to control in children [14].

Hypertension in children in the general population is quite rare, with a prevalence of up to $2 \%-18 \%$, but in children with CKD, the prevalence increases to $50 \%$ or more $[15,16]$. In the cohort studies of CKiD, HTN was detected in $54 \%$ of children with CKD, while the NAPRTCS registry revealed HTN in $76.6 \%$ of patients $[17,18]$. The etiology of hypertension is different depending on the age of diagnosis. In newborns and young children, hypertension occurs due to renovascular diseases such as renal venous thrombosis, renal artery stenosis and other renal parenchymal diseases. HTN more prevalent in preterm neonates, with the presence of umbilical lines, postnatal acute kidney injury, patent ductus, intraventricular hemorrhage, and chronic lung disease, associated with HTN [19, 20, 21].

At the same time, in older children and adolescents, the most common causes of hypertension are characterized by renal parenchymal and renovascular diseases [22, 23]. Children with CKD most often present with secondary HTN, as BP elevation is a common consequence of renal damage and decreased renal function. [4]. The Kidney Disease Outcome and Quality Initiative found the prevalence of HTN in children with CKD to be $70 \%$, and it may even be as high as $80 \%$ in those with stage IV and V CKD [24]. A more recent study of the CKiD cohort found that $52 \%$ of patients whose BP was measured by ambulatory blood pressure measurement (ABPM) met the criteria for HTN [23]. In the NAPRTCS registry cohort, $76 \%$ of children on chronic dialysis had HTN, $57 \%$ of which were cases of uncontrolled HTN requiring further investigation to direct management $[25,18]$.

\section{Pathophysiology of HTN in Children with CKD}

In contrast to adult populations HTN is rarely a direct cause of CKD in children, however, it likely contributes to its progression [26]. Fundamentally, increased blood pressure is caused by an increase in cardiac output and/or of total peripheral resistance. Both can be altered by a plethora of different mechanisms in uremia and renal failure. Additionally, children with certain underlying diseases, e.g. glomerulopathies and polycystic kidney disease, are especially susceptible to hypertension $[3,5]$. HTN is considered a marker for disease severity in CKD and is a risk factor for accelerated deterioration of kidney function as well as for cardiovascular disease [27, 28]. Activation of the renin-angiotensin-aldosterone system plays a pivotal role in renal hypertension. While plasma renin activity is typically found to be markedly elevated only in patients with renal artery stenosis, many patients with CKD have inappropriately normal renin levels (i.e. lower levels would be expected, considering their degree of hypertension and fluid overload [29, 30]. Hyper-reninemia occurs probably due to renin secretion in poorly perfused areas such as cysts and scars or after microangiopathic damage or tubulo-interstitial inflammation [31, 32] and leads to angiotensin II-mediated vasoconstriction as well as aldosterone-mediated salt retention, thus increasing both total peripheral resistance and blood volume. Additional delayed effects of a high angiotensin II tone include inflammation, cardiac hypertrophy and endothelial cell damage, mesangial cell proliferation and fibrosis [10], which contribute further to hypertension and end-organ damage. The sympathetic nervous system plays a critical role at the level of the kidneys with the progression and persistence of pediatric HTN. Sympathetic hyperactivity has been noted in CKD and is thought to be mediated by excess free radical formation, reduced nitric oxide (NO) bioavailability, and excessive production of angiotensin II [33, 34]. In hypertensive patients, an imbalance exists between $\mathrm{NO}$ - a vasodilator and other vasoconstrictors [35]. NO is also known to increase renin, the precursor for the RAAS. The RAAS involves several players: renin is released by juxtaglomerular cells in the kidneys in response to low BP, causing cleavage of angiotensinogen (precursor made in the liver) to angiotensin I. Angiotensin II acts on the zona glomerulosa of the adrenal cortex to release aldosterone in order to increase water absorption and sodium uptake from the distal convoluted tubule and the collecting duct, [34] alters baroreceptor reflexes to higher set points resulting in potentiation of the effects of noradrenaline in the sympathetic nerve terminal; [33] and stimulates the release of antidiuretic hormone from the pituitary to increase water uptake and associated blood volume [36, 37]. HTN, nephron mass, and proteinuria are intimately linked and have compounding effects on one an other, and they are the three main risk factors for CKD progression. Loss of nephron mass leads to glomerular hyperfiltration and increased GFR [38]. Proteinuria is caused either by damage to the glomerular capillary wall or by decrease in tubular reabsorption of protein leading to further destruction of the renal tubular cells - interstitial inflammation and subsequent fibrosis [39, 40, 41]. Albuminuria has also been demonstrated to be an independent risk factor of pediatric HTN [42]. Studies have found that in $62 \%$ of patients, pronounced proteinuria is associated with lower GFR [41].

\subsection{Risk Factors for HTN in CKD in Children}

Obesity in children worldwide is increasing. WHO 
statistics in 2016 indicated that 41 million children under 5 years old and 340 million children and adolescents aged 5 to 19 years were overweight and obese [43]. The prevalence of obesity in the USA was $17 \%$ from 2011 to 2014 in the pediatric population [44]. In Europe, an estimated prevalence of $20 \%$ of children and adolescents are overweight, with onethird of these being considered as obese [45]. In Russia overweight and obesity are $19,9 \%$ and $5,6 \%$ respectively [46]. Obesity, or increased BMI, can now be considered as a risk factor for cardiovascular disease, diabetes and for CKD [47-49].

The increase in CKD in those who are obese is thought to be in part due to increased metabolic demands which, lead to a compensatory glomerular hyperfiltration injury in the kidney [50, 51]. Now its termed obesity-related glomerulopathy, and it has been speculated that a decrease in the number of functional nephrons might also be implicated in the pathogenesis [51]. Obesity can lead to RAAS activation along with other metabolic pathways leading to HTN and the metabolic syndrome [52, 53]. Hyperuricemia is another risk factor for HTN in children and inherited disorders of purine metabolism are the most common cause of hyperuricemia. Hyperuricemia and CKD are closely related, since the accumulation of uric acid is associated with hypertension, metabolic syndrome and microalbuminuria, which are also risk factors for the progression of CKD [54, 55]. $70 \%$ percent of patients with an eGFR $<60 \mathrm{~mL} / \mathrm{min} / 1.73$ $\mathrm{m}^{2}$ had hyperuricemia, compared to $34 \%$ of those with an eGFR > $60 \mathrm{~mL} / \mathrm{min} / 1.73 \mathrm{~m}^{2}[56,57]$.

\subsection{HTN and the State of Target organs in Children with CKD}

Hypertension is a major comorbidity associated with CKD and is one of the main factors contributing to the progression of CKD. HTN-induced target organ damage (TOD) manifests as an injury to several organs: (A) kidney: microalbuminuria/proteinuria, chronic kidney disease [58, 59], (B) eye: retinopathy (1), (C) vessels: increase in intima media thickness, atherosclerosis, reduced arterial compliance (58), (D) brain: cognitive impairment [60], and (E) heart: left ventricular hypertrophy (LVH). [61].

HTN, nephron mass, and proteinuria are intimately linked and have compounding effects on one an other, and they are the three main risk factors for CKD progression [62]. Retinal abnormalities are common in CKD stages 3 to 5, and are more severe and more likely to threaten vision than in hospital patients with CKD stages 1 to 2 [63]. Regarding the fundus of the eye examination, this study reported that, 4 patients $(13.3 \%)$ developed fundus abnormalities, 3 patients $(10 \%)$ had intraretinal Hge and only one patient $(3.3 \%)$ had myopic fundus, meanwhile the most detected retinal microvasculature abnormalities were congested vessels $(33.3 \%)$ then hyperemic disc $(16.7 \%)$ followed by attenuated arteries (13.3\%) [64].

cIMT is significantly elevated among children with CKD as is the prevalence of other cardiovascular risk factors such as hypertension and dyslipidemi and significantly associated with them [1, 65]. LVH (left ventricular hypertrophy) may be evident in hypertensive children with CKD and patient with masked hypertension [66].

Makarova T. et al. detect changes in the cardiac muscle in patients already at the first stage of CKD [67]. A significant increase in the volume of the heart cavities, the thickness of the walls and left ventricular myocardial mass in patients was detected in the terminal stage of CKD [2].

Children with CKD may have low-average cognition compared with the general population, with mild deficits observed across academic skills, executive function, and visual and verbal memory. Limited evidence suggests that children on dialysis may be at greatest risk compared with children with mild to moderate stage CKD and transplant recipients [68].

\section{Diagnosis and Monitoring HTN in Children with CKD}

Hypertension is common in children with chronic kidney disease (CKD) and end-stage renal disease. Hypertension is a known independent risk factor for renal disease progression in children $[69,70]$. It is also a risk factor for left ventricular hypertrophy and increased carotid intima-media thickness in children with CKD $[65,66]$. Diagnosis and monitoring of HTN depends on accurate BP measurements. Several widely used methods for monitoring blood pressure are known: causal BP measurement, self-measured BP and ambulatory blood pressure monitoring (ABPM). With causal BP measurements of blood pressure, it is difficult to make accurate records, since the child often has to sit motionless for 5 minutes to get the records. Simultaneously selfmeasured BP measurements reliability of data is low [4]. ABPM has been shown to be a more accurate technique than causal BP to diagnose hypertension and to stratify cardiovascular risk, especially in patients with CKD stages $3-5$ [22, 71]. In adults and children with CKD, ABPM has been found to be superior than causal blood pressure to diagnose hypertension and to monitor adequacy of treatment [72]. ABPM also correlates better with end organ damage [73]. ABPM uses a wearable, oscillometric BP device that automatically measures and records BPs at fixed intervals (every $20 \mathrm{~min}$ when awake and every $30 \mathrm{~min}$ to $1 \mathrm{~h}$ during sleep) over an entire 24-h period [74]. This allows the assessment of child's overall exposure to elevated BP (BP load) and changes in normal circadian BP pattern. Furthermore, ABPM minimizes the effect of anxiety-induced $\mathrm{BP}$ elevations known as white coat hypertension (WCH) as $\mathrm{BP}$ is monitored over a longer period in the child's own environment [75].] ABPM is also able to diagnose masked hypertension, a condition in which CBP in an office setting is normal, but the BP is found to be high at other times during 24 hours [76]. Masked hypertension is not a benign entity and has been shown to predict end organ damage thus necessitating its detection and management [66]. In children from the CKiD cohort with an eGFR of $30-90 \mathrm{~mL} / \mathrm{min} / 1.73$ 
$\mathrm{m}^{2}, 42 \%$ were normotensive, $4 \%$ had white coat $\mathrm{HTN}, 35 \%$ had masked HTN, and 14\% had ambulatory HTN. BP load was elevated in $52 \%$, while mean BP was elevated in only $32 \%$. Creatinine ratio change was also associated with $39 \%$ higher odds of having an abnormal ABPM [23].

According to Gupta et al. masked hypertension was detected in $19.6 \%$ and $21.7 \%$ had confirmed hypertension. Thirty-four $(73.9 \%)$ children were already receiving antihypertensive medication. In these, casual blood pressure (CBP) was elevated in $23.5 \%$ and ABPM in $47 \%$. Among children with hypertension as defined by ABPM, LVH was detected in $32.2 \%$. It was found that higher the number of abnormal ABPM indices (assessed by BP Index, nocturnal dipping and BP Load) higher the likelihood of LVH. ABPM is better in detecting hypertension and monitoring adequacy of treatment in children with CKD [77].

\section{Treatment}

HTN develops very early in childhood CKD. It is linked with rapid progression of kidney disease, increased morbidity and mortality hence the imperative to start anti-hypertensive medication when blood pressure (BP) is persistently $>$ 90th percentile for age, gender, and height in hypertensive children with CKD [78]. Today known different guidelines on the management of HTN in CKD. In particular [79]. KDIGO guidelines indicate that antihypertensive therapy should be initiated immediately for children with CKD with a BP over the 90th percentile and now also recommends targeting BP $<50$ th percentile for children with CKD and proteinuria. The European Society of Hypertension more recently defined a target $\mathrm{BP}$ reduction to $<75$ th percentile for nonproteinuric CKD and $<50$ th for proteinuric CKD [80]. Usually treatment in children without CKD begin with lifestyle modifications (weight control, healthy diet, sodium reduction, and maintained exercise [5]. Treatment of hypertension in children, with and without CKD, is based on 3 factors: degree of BP elevation, the presence of cardiovascular risk factors, and the presence of target organ damage. The priority for the doctor in the treatment is diet, but in children population difficult control [81].

Another important goal of therapy is the elimination of symptoms and signs of hypertension, as well as damage to target organs. LVH, detected on cardiac echocardiography, is a sensitive tool for detecting damage to the target organ in children with hypertension. LVH is detected in $40 \%$ of these children [82, 83]. However, the first line of therapy in children with HTN and CKD is RAAS. Children receiving RAAS drugs have better control over blood pressure than those receiving other classes of antihypertensive drugs [7, $10]$.

The main drug therapy used in children with HTN and CKD consists of ACE inhibitors. Strict BP control and limitation of proteinuria with ACE inhibition can slow the progression of CKD [57]. According to the results of the ESCAPE study, American Academy of Pediatrics in 2017 recommends the treatment of hypertension in children with
ACE inhibitors or angiotensin receptor blockers (ARB) especially in patients with proteinuria) $[84,85,86]$. ARB and ACE inhibitors, when used together, improve the outcomes of cardiovascular and renal outcomes. Combination therapy is believed to provide a greater antiproteinuric effect than monotherapy [83]. In children with HTN and CKD, lisinopril and enalapril (ACE inhibitors), bisoprolol (beta-1 adrenergic receptor blocker), amlodipine and felodipine (dihydropyridine calcium channel blockers) found to be safe and effective [87, 88, 89]. Often a single agent will be insufficient to achieve currently recommended targets of BP $<50$ th percentile in proteinuric $\mathrm{CKD}$ children and at least $50 \%$ of children will require additional agents [10]. In addition, used diuretics, mainly thiazides, which, reducing the extracellular fluid volume overload and cardiac output, possibly due to a decrease in peripheral vascular resistance, the other important contributor to BP [90]. In the early stages of CKD, thiazides can be effective, but their effectiveness decreases after GFR drops below $60 \mathrm{ml} / \mathrm{min} / 1.73 \mathrm{~m} 2$ and they are ineffective in stages IV and $\mathrm{V}$ of $\mathrm{CKD}$, where furosemide is the best choice [91].

\section{Conclusion}

Thus, HTN is common in children with all stages of CKD. Obesity, hyperuricemia and metabolic syndrome are risk factors for HTN and the progression of CKD. The ABPM is the best method for monitoring blood pressure, and with diet prevents the progression of the disease. Blood pressure and CKD in children are closely linked and often cause a decrease in renal function in children. In CKD in children, hypertension is often masked, and therefore, this is especially important in the treatment, reno and cardioprotection. The best drugs for treating hypertension and CKD are ACE inhibitors, together with other drugs that affect RAAS. It is very important in children with CKD to study the state of target organs, due to their frequent damage, deterioration of their functions and development of complications, which reduces the quality of life of children.

\section{References}

[1] Flynn JT, Mitsnefes M, Pierce C, et al. Blood pressure in children with chronic kidney disease: a report from the Chronic Kidney Disease in Children study. Hypertension. 2008; $\quad 52 \quad$ (4): $631-637 . \quad$ DOI: 0.1161/HYPERTENSIONAHA.108.

[2] Tsygin AN, Arterial hypertension in children. Pediatric Nephrology. E. Leumann, A. N. Tsygin, A. A. Sarkissian (eds). Moscow: Litterra, 2010; 244-251

[3] Ku. E, Kwok J. Definition of CKD. Adolescents with Chronic Kidney Disease. M. N. Haddad, E. Winniki, S. Nguyen (eds). Nature Switzerland AG 2019; 1-2.

[4] Swinford RD, Portman RJ. Measurement and treatment of elevated blood pressure in the pediatric patient with chronic kidney disease. Adv Chronic Kidney Dis. 2004; 11 (2): 143161. DOI: 10.1053/j.arrt.2004.02.001. 
[5] Avner ED et al eds. Chronic Kidney Disease. Pediatric Nephrology. 7th ed. Springer Reference, New York 2016; 2061-2064.

[6] Massengill SF, Ferris M. Chronic kidney disease in children and adolescents. Pediatr Rev. 2014; 35 (1): 16-29. DOI: 10.1542/pir.35-1-16.

[7] Halbach S, Flynn J. Treatment of hypertension in children with chronic kidney disease. Curr Hypertension Rep. 2015; 17 (1): 503. DOI: 10.1007/s11906-014-0503-.

[8] Savenkova N. D. Renal Arterial Hypertension in children and adolescents: causes, classification, diagnosis. Ros Vestn Perinatol i Pediatr 2017; 62: (4): 43-48. DOI: 10.21508/10274065-2017-62-4-43-48.

[9] Mitsnefes M, Flynn J, Cohn S, et al. Masked hypertension associates with left ventricular hypertrophy in children with CKD. J Am Soc Nephrol. 2010; 21 (1): 137-144. DOI: 10.1681/ASN.2009060609 ed.

[10] Hadtstein C, Schaefer F. Hypertension in children with chronic kidney disease: pathophysiology and management. Pediatr Nephrol (Berlin, Germany) 2008; 23 (3): 363-371. DOI: $10.1007 / \mathrm{s} 00467-007-0643-7$.

[11] Harambat J, van Stralen KJ, Kim JJ et al. Epidemiology of chronic kidney disease in children. Pediatr Nephrol 2012; 27: 363-373. DOI: 10.1007/s00467-011-1939-1.

[12] Te Riet L, van Esch JH, Roks AJ, van den Meiracker AH, Danser AH. Hypertension: renin-angiotensin-aldosterone system alterations. Circ Res. 2015; 116 (6): 960-975. DOI: 10.1161/CIRCRESAHA.116.303587.

[13] Wen Chen, Kirstie Ducharme-Smith, Laura Davis, Alvin Wun Fung Hui, Bradley Warady. Dietary Sources of Energy and Nutrient Intake among Children and Adolescents with CKD. Pediatr Nephrol. 2017 Jul; 32 (7): 1233-1241. DOI: 10.1007/s00467-017-3580-0.

[14] Rees L, Mak RH. Nutrition and growth in children with chronic kidney disease. Nat Rev Nephrol. 2011; 7 (11): 615623. DOI: 10.1038/nrneph.2011.137.

[15] Rozanov V. B. Prognostic value of blood pressure in adolescence (22 year prospective observation). Rost Vestn Perinatol Pediat 2006; 5: 27-41.

[16] Karimdzhanov IA, Israilova NA. Chronic kidney disease in children (literature review). Child health. 2017; 12 (7): 146154 (in Russ)] DOI: 10.22141/2224-0551.12.7.2017.116190.

[17] Wuhl E, Hadtstein C, Mehls O, Schaefer F, Escape Trial G. Home, clinic, and ambulatory blood pressure monitoring in children with chronic renal failure. Pediatr Res. 2004; 55 (3):

$492-7$. DOI.org/10.1203/01.PDR.0000106863.90996.76.

[18] Mitsnefes M, Stablein D. Hypertension in pediatric patients on long-term dialysis: a report of the North American Pediatric Renal Transplant Cooperative Study (NAPRTCS). Am J Kidney Dis. 2005; 45 (2): 309-15. DOI: 10.1053/j.ajkd.2004.11.006.

[19] Dionne JM, Abitbol CL, Flynn JT. Hypertension in infancy: diagnosis, management and outcome. Pediatr Nephrol (Berlin, Germany) 2012; 27 (1): 17-32. DOI: 10.1007/s00467-0101755-z.
[20] Flynn JT. Neonatal hypertension: diagnosis and management. Pediatr Nephrol (Berlin, Germany) 2000; 14 (4): 332-341. DOI: $10.1007 / \mathrm{s} 004670050771$.

[21] Flynn JT. Hypertension in the neonatal period. Curr Opin $\begin{array}{llll}\text { Pediatr. 2012; } 24 & \text { (2): 197-204. DOI: }\end{array}$ 10.1097/MOP.0b013e32834f8329.

[22] Tkaczyk M, Stanczyk M, Miklaszewska M, et al. What has changed in the prevalence of hypertension in dialyzed children during the last decade? Ren Fail. 2017; 39 (1): 283-289. DOI: $10.1080 / 0886022 X .2016 .1260033$.

[23] Samuels J, Ng D, Flynn JT, et al. Ambulatory blood pressure patterns in children with chronic kidney disease. Hypertension. 2012; 60 (1): 43-50. tDOI.org/10.1161/HYPERTENSIONAHA.111.189266.

[24] Wong H, Mylrea K, Feber J, Drukker A, Filler G. Prevalence of complications in children with chronic kidney disease according to KDOQI. Kidney Int. 2006; 70 (3): 585-590. DOI: $10.1038 /$ sj.ki.5001608.

[25] Agarwal R, Flynn J, Pogue V, Rahman M, Reisin E, Weir MR. Assessment and management of hypertension in patients on dialysis. J Am Soc Nephrol. 2014; 25 (8): 1630-1646. DOI: 10.1681/ASN.2013060601.

[26] Horowitz B, Miskulin D, Zager P. Epidemiology of hypertension in CKD. Adv Chronic Kidney Dis. 2015; 22 (2): 88-95. DOI: 10.1053/j.ackd.2014.09.004.

[27] Klag MJ, Whelton PK, Randall BL, et al. Blood pressure and end-stage renal disease in men. N Engl J Med. 1996; 334 (1): 13-18. DOI: 10.1056/NEJM199601043340103.

[28] Middleton RJ, Parfrey PS, Foley RN. Left ventricular hypertrophy in the renal patient. J Am Soc Nephrol. 2001; 12 (5): 1079-1084. PMID: 11316868.

[29] Brass H, Ochs HG, Armbruster H, Heintz R. Plasma renin activity (PRA) and aldosterone (PA) in patients with chronic glomerulonephritis (GN) and hypertension. Clin Nephrol 1976; 5: 57-60. PMID: 943254.

[30] Warren DJ, Ferris TF, Renin secretion in renal hypertension. Lancet.1970 1: $159-162$. DOI: $10.1016 / \mathrm{s} 0140$ 6736(70)90404-6.

[31] Loghman-Adham M, Soto CE, Inagami T, Cassis L. The intrarenal renin-angiotensin system in autosomal dominant polycystic kidney disease. Am J Physiol Renal Physiol. 2004; 287: F775-F788. DOI: 10.1152/ajprenal.00370.2003.

[32] Wolf G, Butzmann U, Wenzel UO. The renin-angiotensin system and progression of renal disease: from hemodynamics to cell biology. Nephron Physiol. 2003 93: P3-P13. DOI: $10.1159 / 000066656$.

[33] Schiffrin EL, Lipman ML, Mann JF. Chronic kidney disease: effects on the cardiovascular system. Circulation. 2007; 116 (1): 85-97. DOI: 10.1161/CIRCULATIONAHA.106.678342.

[34] Thomas P, Dasgupta I. The role of the kidney and the sympathetic nervous system in hypertension. Pediatr Nephrol (Berlin, Germany) 2015; 30 (4): 549-560. DOI: 10.1007/s00467-014-2789-4.

[35] Reid IA. Role of nitric oxide in the regulation of renin and vasopressin secretion. Front Neuroendocrinol. 1994; 15 (4): 351-383. DOI: 10.1006/frne.1994.1014. 
[36] Urushihara M, Kagami S. Role of the intrarenal renin-angiotensin system in the progression of renal disease. Pediatr Nephrol (Berlin, Germany) 2016: 1-9. DOI: 10.1007/s00467-016-3449-7.

[37] Joppich R, Weber P. Effects of ADH on the activity and function of the renin-angiotensin-aldosterone system in infants and in children. Eur J Pediatr. 1976; 122 (4): 303-308. https://doi.org/10.1007/BF00481512.

[38] Noone D, Licht C. Chronic kidney disease: a new look at pathogenetic mechanisms and treatment options. Pediatr Nephrol (Berlin, Germany) 2014; 29 (5): 779-792. DOI: 10.1007/s00467-013-2436-5.

[39] D'Amico G, Bazzi C. Pathophysiology of proteinuria. Kidney Int. 2003; 63 (3): 809-825. DOI: $10.1046 / j .1523-$ 1755.2003.00840.x.

[40] Eddy AA. Progression in chronic kidney disease. Adv Chronic Kidney Dis. 2005; 12 (4): 353-365. DOI: 10.1053/j.ackd.2005.07.011.

[41] Wong CS, Pierce CB, Cole SR, et al. Association of proteinuria with race, cause of chronic kidney disease, and glomerular filtration rate in the chronic kidney disease in children study. Clin J Am Soc Nephrol. 2009; 4 (4): 812-819. DOI: $10.2215 / \mathrm{CJN} .01780408$.

[42] Inker LA, Coresh J, Levey AS, Tonelli M, Muntner P. Estimated GFR, albuminuria, and complications of chronic kidney disease. J Am Soc Nephrol. 2011; 22 (12): 2322-2331. DOI: 10.1681/ASN.2010111181.

[43] WHO Updated Factsheet 2016. Obesity and owerweight. http://www.who.int/mediacentre/factsheets/fs311/ru.

[44] Ogden CL, Carroll MD, Fryar CD, Flegal KM. Prevalence of obesity among adults and youth: United States, 2011-2014. NCHS Data Brief. 2015; (219): 1-8. http://www.cdc.gov/nchs/products/databriefs.htm.

[45] Cattaneo A, Monasta L, Stamatakis E, et al. Overweight and obesity in infants and pre-school children in the European Union: a review of existing data. Obes Rev. 2010; 11 (5): 389-398. DOI: 10.1111/j.1467-789X.2009.00639.x.

[46] Dzhumagaziev AA., Bezrukova DA., Bogdanyants MV et al. Obesity in Children in the Modern World: Realities and Possible Solutions. Current Pediatrics. 2016; 15 (3): 250-256. https://doi.org/10.15690/vsp.v15i3.1561.

[47] Kovesdy CP, Furth S, Zoccali C. Obesity and kidney disease: hidden consequences of the epidemic. Rev Med Chil. 2017; 145 (3): 281-291. DOI: 10.4103/ijn.IJN_61_17.

[48] Foster MC, Hwang SJ, Larson MG, et al. Overweight, obesity, and the development of stage $3 \mathrm{CKD}$ : the Framingham Heart Study. Am J Kidney Dis. 2008; 52 (1): 39-48. DOI: 10.1053/j.ajkd.2008.03.003.

[49] Kanasaki K, Kitada M, Kanasaki M, Koya D. The biological consequence of obesity on the kidney. Nephrol Dial Transplant. 2013; 28 (Suppl 4): iv1-iv7. https://doi.org/10.1093/ndt/gft098.

[50] Savino A, Pelliccia P, Chiarelli F, Mohn A. Obesity-related renal injury in childhood. Horm Res Paediatr. 2010; 73 (5): 303-311. DOI: 10.1159/000308161.

[51] Tsuboi N, Utsunomiya Y, Hosoya T. Obesity-related glomerulopathy and the nephron complement. Nephrol Dial
Transplant. 2013; 28 (Suppl 4): iv108-iv113. DOI: $10.1093 / \mathrm{ndt} / \mathrm{gft} 258$.

[52] Ruster C, Wolf G. The role of the renin-angiotensinaldosterone system in obesity-related renal diseases. Semin Nephrol. 2013; 33 (1): 44-53. DOI: 10.1016/j.semnephrol.2012.12.002.

[53] Litwin M, Niemirska A. Metabolic syndrome in children with chronic kidney disease and after renal transplantation. Pediatr Nephrol (Berlin, Germany) 2014; 29 (2): 203-216. DOI: 10.1007/s00467-013-2500-1.

[54] Grayson PC, Kim SY, LaValley M, Choi HK. Hyperuricemia and incident hypertension: a systematic review and metaanalysis. Arthritis Care Res (Hoboken). 2011 Jan; 63 (1): 10210. DOI: $10.1002 /$ acr.20344.

[55] Nashar K, Fried LF. Hyperuricemia and the progression of chronic kidney disease: is uric acid a marker or an independent risk factor? Adv Chronic Kidney Dis. 2012; 19 (6): 386-391. DOI: 10.1053/j.ackd.2012.05.004.

[56] Noone DG, Marks SD. Hyperuricemia is associated with hypertension, obesity, and albuminuria in children with chronic kidney disease. J Pediatr. 2013; 162 (1): 128-132.

[57] Rodenbach KE, Schneider MF, Furth SL, et al. Hyperuricemia and progression of CKD in children and adolescents: the chronic kidney disease in children (CKiD) cohort study. Am J Kidney Dis. 2015; 66 (6): 984-992. DOI: 10.1053/j.ajkd.2015.06.015.

[58] Assadi F. Effect of microalbuminuria lowering on regression of left ventricular hypertrophy in children and adolescents with essential hypertension. Pediatr Cardiol. 2007; 28 (1): 27 33. DOI: $10.1007 / \mathrm{s} 00246-006-1390-4$.

[59] Conkar S, Yılmaz E, Hacıkara Ş, Bozabalı S, Mir S. Is daytime systolic load an important risk factor for target organ damage in pediatric hypertension? J Clin Hypertens. Greenwich. 2015; 17 (10): 760-6. DOI: 10.1111/jch.12608.

[60] Lande MB, Batisky DL, Kupferman JC, Samuels J, Hooper SR, Falkner B, et al. Neurocognitive function in children with primary hypertension. J Pediatr. 2017; 180: 148-55.e1. DOI: 10.1016/j.jpeds.2016.08.076.

[61] Kupferman JC, Aronson Friedman L, Cox C, Flynn J, Furth S, Warady B, et al. BP control and left ventricular hypertrophy regression in children with CKD. Clin J Am Soc Nephrol. 2014; 25 (1): 167-74. DOI: 10.1681/ASN.2012121197.

[62] Staples A, Wong C. Risk Factors for Progression of Chronic Kidney Disease Curr Opin Pediatr. 2010 Apr; 22 (2): 161-169. DOI: 10.1097/MOP.0b013e328336ebb0.

[63] Deva R, Alias MA, Colville D, Tow FK, Ooi QL. Visionthreatening retinal abnormalities in chronic kidney disease stages 3 to 5. Clin J Am Soc Nephrol. 2011 Aug; 6 (8): 186671. DOI: $10.2215 /$ CJN.10321110.

[64] El-Ghany, S. M. A., El-Salam, M. A., Farag, M. M. and ElAshwah, O. A. (2019) Ocular Changes in Egyptian Children on Regular Hemodialysis. International Journal of Clinical Medicine, 10, 353-362.

[65] Brady TM, Schneider MF, Flynn JT, Cox C, Samuels J. et al.. Carotid Intima-Media Thickness in Children with CKD: Results from the CKiD Study. Clin J Am Soc Nephrol. 2012; 7: 1930-1937. DOI: 10.2215/CJN.0313031. 
[66] Sinha MD, Tibby SM, Rasmussen P, et al. Blood pressure control and left ventricular mass in children with chronic kidney disease. Clin J Am Soc Nephrol. 2011; 6 (3): 543-551. DOI: $10.2215 / \mathrm{CJN} .04690510$.

[67] Makarova T. P., Melnikova Yu. S. Echocardiographic parameters of the heart with chronic kidney disease in children and adolescents. Ros Vestn Perinatol i Pediatr 2017; 62: (5): 149-152. DOI: 10.21508/1027-4065-2017-62-5-149-152.

[68] Chen K., Didsbury M., Van Zwieten A., Howell M., Kim S. et al. Neurocognitive and Educational Outcomes in Children and Adolescents with CKD. A Systematic Review and MetaAnalysis. CJASN, March 2018; 13 (3): 387-397; DOI: https://doi.org/10.2215/CJN.09650917.

[69] Staples AO, Greenbaum LA, Smith JM, Gipson DS, Filler G, Warady BA, et al. Association between clinical risk factors and progression of chronic kidney disease in children. Clin J Am Soc Nephrol. 2010; 5: 2172-9. DOI: 10.2215/CJN.07851109.

[70] Kamath N, Iyengar A, George N, Luyckx VA. Risk Factors and Rate of Progression of CKD in Children. Kidney Int Rep 2019; 4 : 1472-77. https://doi.org/10.1016/j.ekir.2019.06.004.

[71] Chaudhuri A, Sutherland SM, Begin B, Salsbery K, McCabe L, Potter D, et al. Role of twenty-four-hour ambulatory blood pressure monitoring in children on dialysis. Clin J Am Soc Nephrol. 2011; 6: 870-6. DOI: 10.2215/CJN.07960910.

[72] Hermida RC, Smolensky MH, Ayala DE, Portaluppi F, Crespo JJ, Fabbian F, et al. Ambulatory blood pressure monitoring recommendations for the diagnosis of adult hypertension, assessment of cardiovascular and other hypertensionassociated risk, and attainment of therapeutic goals (summary). Joint recommendations from the International Society for Chronobiology (ISC), American Association of Medical Chronobiology and Chronotherapeutics (AAMCC), Spanish Society of Applied Chronobiology, Chronotherapy, and Vascular Risk (SECAC), Spanish Society of Atherosclerosis (SEA), and Romanian Society of Internal Medicine (RSIM) Clin Investig Arterioscler. 2013; 25: 74-82. DOI: 10.1016/j.arteri.2013.03.002.

[73] Mancia G, Parati G. Ambulatory blood pressure monitoring and organ damage. Hypertension. 2000; 36: 894-900 DOI: 10.1161/01.hyp.36.5.894.

[74] Flynn JT, Daniels SR, Hayman LL, Maahs DM, McCrindle BW, Mitsnefes M, et al. Update: Ambulatory blood pressure monitoring in children and adolescents: A scientific statement from the American Heart Association. Hypertension. 2014; 63: 1116-35.

[75] Franklin SS, Thijs L, Hansen TW, O'Brien E, Staessen JA. White-coat hypertension: New insights from recent studies. Hypertension. 2013; 62: 982-7. DOI: 10.1161/HYPERTENSIONAHA.113.01275.

[76] Urbina E, Alpert B, Flynn J, Hayman L, Harshfield GA, Jacobson $\mathrm{M}$, et al. Ambulatory blood pressure monitoring in children and adolescents: Recommendations for standard assessment: A scientific statement from the American Heart Association Atherosclerosis, Hypertension, and Obesity in Youth Committee of the council on cardiovascular disease in the young and the council for high blood pressure research. Hypertension. 2008; 52: 433-51. DOI: 10.1161/HYPERTENSIONAHA.108.190329.
[77] Gupta D, S. Chaturvedi S, S. Chandy S, and Agarwal I Role of 24-h ambulatory blood pressure monitoring in children with chronic kidney disease Indian J Nephrol. 2015; 25 (6): 355361. DOI: $10.4103 / 0971-4065.148305$.

[78] Olowu WA. Pre-treatment considerations in childhood hypertension due to chronic kidney disease. World J Nephrol. 2015 Nov; 6; 4 (5): 500-10. DOI: 10.5527/wjn.v4.i5.50.

[79] Wheeler DC, Becker GJ. Summary of KDIGO guideline. What do we really know about management of blood pressure in patients with chronic kidney disease? Kidney Int. 2013; 83 (3): 377-383. DOI: 10.1038/ki.2012.425.

[80] Lurbe E, Cifkova R, Cruickshank JK, et al. Management of high blood pressure in children and adolescents: recommendations of the European Society of Hypertension. J Hypertens. 2009; 27 (9): 1719-1742. DOI: 10.1097/HJH.0b013e32832f4f6b.

[81] Gallibois C. M, Jawa NA, and G Noone DG. Hypertension in pediatric patients with chronic kidney disease: management challenges. Int J Nephrol Renovasc Dis. 2017; 10: 205-213. DOI: $10.2147 /$ IJNRD.S100891.

[82] Rogan JW, Lyszkiewicz DA, Blowey D, Khattak S, Arbus GS, Koren G. A randomized prospective crossover trial of amlodipine in pediatric hypertension. Pediatr Nephrol (Berlin, Germany) 2000; 14 (12): 1083-1087. DOI: $10.1007 / \mathrm{s} 004670000400$.

[83] Flynn JT, Kaelber DC, Baker-Smith CM, Blowey D, Carroll AE, Daniels SR, et al. Clinical practice guideline for screening and management of high blood pressure in children and adolescents. Pediatrics. 2017; 140: e20171904 DOI: 10.1542/peds.2017-1904.

[84] Berl T. Review: renal protection by inhibition of the reninangiotensin-aldosterone system. J Renin Angiotensin Aldosterone Syst. 2009; $10 \quad$ (1): $1-8 . \quad$ DOI: $10.1177 / 1470320309102747$.

[85] ESCAPE Trial Group, Wühl E, Trivelli A, Picca S, Litwin M, Peco-Antic A, et al. Strict blood-pressure control and progression of renal failure in children. N Engl J Med. 2009; 361 (17): 1639-50. DOI: 10.1056/NEJMoa0902066.

[86] Lou-Meda R, Stiller B, Antonio ZL, Zielinska E, Yap HK, Kang HG. Long-term safety and tolerability of valsartan in children aged 6 to 17 years with hypertension. Pediatr Nephrol. 2019 Mar; 34 (3): 495-506. DOI: 10.1007/s00467018-4114-0.

[87] Wells T, Frame V, Soffer B, et al. A double-blind, placebocontrolled, dose-response study of the effectiveness and safety of enalapril for children with hypertension. J Clin Pharmacol. 2002; 42 (8): 870-880. DOI: 10.1177/009127002401102786.

[88] Trachtman H, Frank R, Mahan JD, et al. Clinical trial of extended-release felodipine in pediatric essential hypertension. Pediatr Nephrol (Berlin, Germany) 2003; 18 (6): 548-553. DOI: $10.1007 / \mathrm{s} 00467-003-1134-0$.

[89] Chaturvedi S, Lipszyc DH, Licht C, Craig JC, Parekh R. Pharmacological interventions for hypertension in children. Cochrane Database Syst Rev. 2014; (2): CD008117. DOI: 10.1002/14651858.CD008117.pub2.

[90] Vasavada N, Agarwal R. Role of excess volume in the pathophysiology of hypertension in chronic kidney disease. Kidney Int. 2003; 64 (5): 1772-1779. DOI: 10.1046/j.15231755.2003.00273.x. 
[91] Blowey DL. Diuretics in the treatment of hypertension. Pediatr Nephrol (Berlin, Germany) 2016; 31 (12): 2223-2233. DOI: $10.1007 / \mathrm{s} 00467-016-3334-4$. 